\title{
Percutaneous Radiofrequency Facet Rhizotomy - Experience with 118 Procedures and Reappraisal of its Value
}

\author{
Wen-Ching Tzaan and Ronald R. Tasker
}

\begin{abstract}
Background: There have been many reports of percutaneous radiofrequency facet rhizotomy, perhaps better referred to as facet denervation, usually performed under general anaesthesia, with inconsistent success rates. Objectives: To report the authors' outcome data using both general and local anaesthesia and to reassess the value of this controversial procedure. Methods: Our experience with 118 consecutive percutaneous radiofrequency facet rhizotomies performed on 90 patients in the Toronto Western Hospital was analyzed. Sixty percent of the procedures were performed under general anaesthesia, 40\% under local anaesthesia. All patients had been temporarily virtually relieved of pain after local anaesthetic blockade of the subject facets by an independent radiologist. Results: The patients were monitored from $1-33$ (mean 5.6) months after surgery, with complete elimination or a greater than $50 \%$ subjective reduction of pain considered the criteria for success. For the first or only procedure this was $41 \%$ overall, $37 \%$ in cases done under local anaesthesia, $46 \%$ in cases done under general anaesthesia (difference not statistically significant $\mathrm{p}=0.52$ ). There was no statistically significant difference in success rates for procedures performed in the cervical, thoracic or lumbosacral facets, with unilateral versus bilateral denervations, when two to three as compared with more than three facets were denervated, nor for operations done in patients who had had previous spinal surgery compared with those who had not. Results were not better regardless of whether hyperextension of the spine aggravated the patient's preoperative pain or not, and when the procedures were repeated in the same patient outcomes tended to be consistent, arguing against repetition of failed facet denervations. The morbidity was low, the chief problem being sensory loss and transient neuropathic pain in the distribution of cutaneous branches of posterior rami in the cervical and thoracic areas; mortality was zero. Conclusions: Percutaneous radiofrequency facet denervation is simple and safe, still worth considering in patients with disabling spinal pain that fails to respond to conservative treatment. The use of general anaesthesia shortens the operating time and the patient's discomfort without impairing success rate.
\end{abstract}

RÉSUMÉ: Rhizotomie parcourants de radiofréquence percutanée - Expérience et réévaluation à la lumière de 118 interventions. Introduction: Il existe plusieurs rapports sur la rhizotomie par courants de radiofréquence percutanée, peut-être mieux connue sous le nom de dénervation facettaire, habituellement effectuée sous anesthésie générale avec des taux de succès variables. Objectifs: De rapporter les résultats des auteurs avec l'anesthésie générale et l'anesthésie locale et de réévaluer la valeur de cette procédure controversée. Méthodes: Nous avons analysé 118 cas consécutifs de rhizotomies par courants de radiofréquence percutanée effectuées sur 90 patients au Toronto Western Hospital. Soixante pourcent de ces interventions ont été effectuées sous anesthésie générale et $40 \%$ sous anesthésie locale. Tous les patients avaient été entièrement soulagés de leur douleur par une anesthésie locale des facettes impliquées, administrée par un radiologiste indépendant. Résultats: Les patients ont été évalués de 1 à 33 mois après la chirurgie (moyenne de 5.6 mois) et le critère de succès utilisé était une élimination complète ou une diminution subjective de plus de 50\% de la douleur. Pour la première ou l'unique intervention, le taux de succès était de $41 \%$, soit $37 \%$ des cas effectués sous anesthésie locale et $46 \%$ des cas effectués sous anesthésie générale ( $\mathrm{p}=0.52$ ). Il n'y avait pas de différence statistiquement significative dans le taux de succès pour les interventions effectuées au niveau de facettes cervicales, thoraciques ou lombaires; pour les interventions unilatérales ou bilatérales; quand deux ou trois facettes par rapport à plus de trois étaient dénervées; pour les interventions faites chez des patients qui avaient subi une chirurgie spinale antérieure par rapport à ceux qui n'en avaient pas subi. Les résultats n'étaient pas meilleurs si l'hyperextension de la colonne aggravait la douleur préopératoire ou pas. Quand l'intervention était répétée chez le même patient, les résultats avaient tendance à être les mêmes, ce qui va contre la répétition de l'échec de l'intervention. La morbidité était faible, le problème le plus fréquent étant une perte sensitive et des douleurs névropathiques transitoires dans le territoire des branches cutanées des racines postérieures dans les régions cervicales et thoraciques; la mortalité était nulle. Conclusions: La dénervation par courants de radiofréquence percutanée est simple et peut être effectuée en toute sécurité, et mérite d'être considérée chez les patients qui ont des douleurs spinales invalidantes qui ne répondent pas au traitement conservateur. L'utilisation de l'anesthésie générale diminue le temps opératoire et l'inconfort pour le patient, sans altérer le taux de succès.

Can. J. Neurol. Sci. 2000; 27: 125-130

The speculation that the facet joint (FJ) can be a source of spinal pain was first proposed in 1910 and examined by Goldthwait in 1911. ${ }^{1}$ In 1927, Putti focused specifically on degenerative processes in the articular facets ${ }^{2}$ and suggested the possibility that they might constitute nonmechanical sources of nerve irritation. Not until 1933 was the term "facet syndrome"
From the Second Division of Neurosurgery, Chang Gung University and Chang Gung Memorial Hospital, Taoyuan, Taiwan (W.C.T.); and the Division of Neurosurgery, Toronto Western Hospital, University Health Network and the Department of Surgery, University of Toronto (R.R.T.).

RECEIVED SEPTEMBER 17, 1998. ACCEPTEDIN FINALFORMJUNE 17, 1999. Reprint requests to: Wen-Ching Tzaan, M.D., Department of Neurosurgery, Chang Gung Memorial Hospital, 5 Fu-Shing Street, 333, Kweishan, Taoyuan, Taiwan. 
introduced by Ghormley, ${ }^{3}$ but after the advent and evolution of the theory of herniation of the nucleus pulposus, attention to the FJ as a source of back pain faded. However, many clinical problems, unexplainable by knowledge of disc herniation and unresolved by the surgical removal of the herniated disc, led Badgley to redirect attention to the $\mathrm{FJ}^{4}{ }^{4}$

Facet syndrome presents as steady pain in the mid-posterior aspect of the neck or back that may extend over a variable number of vertebral levels and that may spread symmetrically or asymmetrically laterally as far as the proximal limb sclerotomally but not dermatomally. Hyperextension of the neck or back is often said to aggravate the pain and FJ disease is not responsible for any neurological deficit. It was not until 1971 that a specific treatment for facet syndrome emerged, when Rees ${ }^{5}$ inserted a hooked knife into the back beside the suspect FJ under local anaesthesia, claiming a near $100 \%$ short-term success rate. Shealy also employed Rees's method and obtained promising results, but the attempt to denervate the FJ thoroughly led to huge subcutaneous hematomas in several cases. ${ }^{6,7}$ Shealy, therefore, modified the Rees technique, being the first to use a fluoroscope and electrical stimulation to localize the nerve and a radiofrequency (RF) generator to destroy it, reporting a $79 \%$ success rate in patients who had not previously had spinal surgery. 7,8 After Shealy's report, many articles followed describing experience with percutaneous radiofrequency facet rhizotomy (PRFFR). ${ }^{9-29}$

The methods for screening patients to undergo PRFFR, the methods for facet nerve localization, the size of electrode used, parameters for the RF lesions made and the results reported, varied widely. The present report describes our experience with PRFFR under local and general anaesthesia and examines the clinical features of the pain and levels of surgery as they related to outcome.

\section{MATERIALS AND METHODS}

From October 1983 to December 1994118 PRFFR procedures were performed in the Toronto Western Hospital (TWH) on 90 patients, 57 males, 33 females aged 23 to 83 (mean 43) years. Four patients who underwent the procedure at different levels on separate occasions were treated as eight separate individuals in the results. Twenty-three of the 118 procedures were repeated at the same or overlapping levels, one twice at the same level but these repeated procedures were not evaluated. Follow-up was 1-33 months (mean, 5.6) months.

\section{Patient selection}

All patients had what was considered by the authors as appropriate facet syndrome pain of at least six months duration that was refractory to conservative treatment including bed rest, physical therapy, analgesics and muscle relaxants for at least six weeks. Plain radiography, myelography, computed tomography or magnetic resonance imaging studies were performed to exclude the possibility of pathology that was amenable to primary therapy. All patients reported at least $50 \%$ reduction of their pain after local anaesthetic blockade of the facet joints to be denervated was performed and assessed by a radiologist, who was independent of the surgical team.

All of the procedures were done by, or under the supervision of, the senior author (RRT). Before 1991, the procedures were done under local anaesthesia; after that, under general anaesthesia. Bilateral denervation was done in patients suffering from midline pain or pain on both sides of the trunk while unilateral denervation was done in those with strictly unilateral pain. FJs were denervated from one vertebral level above to one below the patient's level of significant pain or to the level of the $\mathrm{S} 1$ vertebra. Patients were positioned prone with a C-arm image intensifier affording an anteroposterior view of the appropriate level of the spine. The suitably prepped skin was pierced with a \#11 scalpel blade at appropriate sites under fluoroscopic guidance and \#14 spinal needles introduced to the targets. Local anaesthetic was used at this stage in procedures not performed under general anaesthesia. The stylets of the spinal needles were then replaced with appropriate electrodes and the spinal needles partially withdrawn around them so as not to encroach on the bare tip. The electrodes were approximately $15 \mathrm{~cm}$ in length, 1.1 $\mathrm{mm}$ in diameter and insulated, except for their terminal $5 \mathrm{~mm}$ (available from DIROS Technology, Ontario.)

FJs are innervated by the articular nerve of the medial branch of the posterior primary ramus (PPR) from the segment above the joint with contributions from the next more cephalad level. ${ }^{14,30-37}$ For example, the L4-5 FJs receive their nerve supply from the medial branch of the PPR of L3 and L4. FJ denervation should ideally destroy only the articular nerve but, in practice the proximal segment of the PPR (its medial branch) is usually disrupted in the lumbosacral segment, and the PPR, per se, is disrupted in the cervical and thoracic areas because of their greater anatomical consistency.

With anteroposterior imaging, the nerve is sought in the lateral notch of the lateral mass of the vertebral body in the cervical spine, between two adjacent ribs in the thoracic spine and at the junction of the superior edge of the transverse process and lateral rim of the pedicle at L1-4, the lumbosacral notch at L, and the superior rim of the first dorsal sacral foramen at S1.

Physiological localization by electrical stimulation was then done at $2 \mathrm{~Hz}$ and $100 \mathrm{~Hz}$ in those patients operated on under local anaesthesia and at $2 \mathrm{~Hz}$ in those receiving general anaesthesia, $100 \mathrm{~Hz}$ stimulation in the awake patient induced paraesthesiae below 2 volts, without extension beyond the proximal part of the appropriate ipsilateral limb, even with suprathreshold stimulation (OWL RF generator DIROS Technology was used). Stimulation at $2 \mathrm{~Hz}$ evoked contraction of ipsilateral paraspinal muscles below 1-2 volts, without contractions in the appropriate limb musculature, below 7 volts (signifying a safe distance between electrode tip and anterior ramus). If there were unsuitable responses to stimulation, electrode position was changed and stimulation repeated until suitable responses occurred. If no response occurred, or one at an undesirably high voltage despite repeated attempts, localization was then based on radiological criteria alone, a situation most common at the L5-S1 segments. When the procedure was performed under local anaesthesia, additional sedation or anaesthetic was given at the time of lesion making. We came to prefer the use of general anaesthesia in order to reduce the patient's discomfort and found that this shortened the procedure by 30 minutes or more. Though the sensory responses in the conscious patient were useful for localization, they were often unreliable because of distraction by discomfort or sedation.

Once the electrode tip was suitably positioned, an RF lesion 
was made at each site, step-wise fashion, starting at $80^{\circ} \mathrm{C}$ for 90 seconds, gradually increasing current flow and recorded temperature until current "fall-off" occurred, indicating that a maximum lesion size had been achieved. Current flow varied between different sites, reflecting varying tissue impedance. Single RF lesions were made at each level, unless premature current fall-off occurred when the electrode was repositioned and the whole procedure repeated.

Patients were usually discharged home on the day of surgery and required analgesic medication for the first five days.

\section{RESULTS}

All results are based on the first or only procedure done in each patient at the particular level stated.

Table 1 lists the procedures performed and Table 2 the number and percentage of first or only procedures that were successful in each patient, $41 \%$ overall. Results were not statistically significantly different for procedures at different levels. Table 3 compares unilateral and bilateral first procedures, there being no statistically significant differences between the two groups. Table 4 shows the success rate in relationship to the number of facet joints denervated at the first or only procedures in the lumbosacral region, there being no statistically significant differences between patients denervated at two to three or over three segments. Thus, the laterality and the number of segments of denervation did not significantly affect the chance of success. Table 5 compares results in procedures done under local and general anaesthesia; $37 \%$ of procedures done under local and $46 \%$ under general anaesthesia were successful, there being no statistically significant difference $(\mathrm{p}=0.5246)$. Among the 71 procedures done on our patients who had not previously had spinal surgery, 31 (44\%) experienced successful pain relief while nine of the $24(38 \%)$ procedures done on patients who had previously had spinal surgery were successful $(\mathrm{p}=0.7722)$, a statistically insignificant difference. It is commonly believed that pain originating in facet joints is especially aggravated by extension of the spine. ${ }^{13,18}$ Table 6 shows that in our patients, $39 \%$ of those with pain aggravated by extension, enjoyed successful results. Of the patients with pain not aggravated by externsion, $47 \%$ of the procedures were successful (no significant difference). Mooney ${ }^{38}$ reported similar results. Finally, we examined the reproducibility of the results in 22 patients who underwent repeated denervations, at the same or overlapping levels, on different occasions. In 16 patients, the results were the same on both occasions; eight patients having successful results and seven unsuccessful results on both occasions; one patient had unsuccessful results on three occasions. In four patients, results were inconsistent and two could not be followed after the repeated procedure. The consistency is statistically significant $(\mathrm{p}=0.0055)$ suggesting that if a first facet denervation fails, there is a low chance that repetition will succeed.

\section{Complications}

Table 7 lists complications. Four patients complained of aggravation of their pain after their procedure for no apparent reason. Twelve developed burning pain or dysaesthesia, often associated with some degree of sensory loss and/or with allodynia or hyperpathia, in the paravertebral skin at the levels of
Table 1: Location and number of total procedures, repeated procedures, and segments denervated.

\begin{tabular}{lccc}
\hline $\begin{array}{l}\text { Level of } \\
\text { procedure }\end{array}$ & $\begin{array}{c}\text { Total no. of } \\
\text { procedures }\end{array}$ & $\begin{array}{c}\text { No. of } \\
\text { procedures } \\
\text { repeated at same } \\
\text { level }\end{array}$ & $\begin{array}{l}\text { No. of facet joints } \\
\text { denervated (mean) } \\
\text { in each patient }\end{array}$ \\
Cervical & 13 & 2 & $2-5(3.5)$ \\
Thoracic & 17 & 2 & $2-5(3.5)$ \\
Lumbosacral & 88 & 19 & $2-6(3.5)$ \\
Total & 118 & 23 & $2-6(3.5)$ \\
\hline
\end{tabular}

Table 2: Success rate of first or only facet denervations at each level (mean follow-up $=5.6$ months).

\begin{tabular}{lcc}
\hline Level & $\begin{array}{c}\text { Proportion of } \\
\text { successful procedures }\end{array}$ & $\%$ \\
Cervical & $5 / 11$ & $45^{*}$ \\
Thoracic & $6 / 15$ & $40^{*}$ \\
Lumbosacral & $28 / 69$ & $41^{*}$ \\
Total & $39 / 95$ & 41 \\
\hline
\end{tabular}

*Difference is not significant, $\mathrm{p}=0.9506$

Table 3: Comparison of success rate in unilateral vs bilateral procedures.

\begin{tabular}{lcc}
\hline $\begin{array}{l}\text { Side of } \\
\text { facet denervation }\end{array}$ & $\begin{array}{c}\text { Proportion of } \\
\text { successful procedures }\end{array}$ & $\%$ \\
Unilateral & $12 / 33$ & $36^{*}$ \\
$\quad$ All levels & $6 / 18$ & $33^{*}$ \\
$\quad$ Lumbosacral & $28 / 62$ & $45^{*}$ \\
Bilateral & $23 / 51$ & $45^{*}$ \\
$\quad$ All levels & & \\
\hline
\end{tabular}

*Differences are not significant, $\mathrm{p}=0.5427$ in all levels, $\mathrm{p}=0.5541$ in lumbosacral cases.

the facets denervated. This resolved after a few months in every case and was interpreted as neuropathic pain from interference with the cutaneous branches of the posterior rami, incidentally confirming that the posterior rami had been denervated. One patient complained of transient leg pain after the procedure, which was attributed to possible heating of the sensory portion of the ventral ramus, while two reported subjective leg weakness, 
Table 4: Number of facet joints denervated vs success rate in the lumbosacral spine.

\begin{tabular}{lcccc}
\hline $\begin{array}{l}\text { No. of } \\
\text { joints } \\
\text { denervated }\end{array}$ & $\begin{array}{c}\text { Proportion of } \\
\text { successes in } \\
\text { unilateral procedures }\end{array}$ & $\%$ & $\begin{array}{c}\text { Proportion of } \\
\text { successes in } \\
\text { bilateral procedures }\end{array}$ & $\%$ \\
$2-3$ & $5 / 12$ & $42^{*}$ & $7 / 20$ & $35^{*}$ \\
$>3$ & $1 / 6$ & $17^{*}$ & $16 / 31$ & $52^{*}$ \\
\hline
\end{tabular}

*Differences are not significant; $\mathrm{p}=0.600$ in unilateral procedures; $\mathrm{p}=$ 0.3811 in bilateral procedures.

Table 5: Comparison of results for procedures done under local and general anaesthesia.

\begin{tabular}{lcc}
\hline $\begin{array}{l}\text { Anaesthetic } \\
\text { method }\end{array}$ & $\begin{array}{c}\text { Proportion of } \\
\text { successful procedures }\end{array}$ & $\%$ \\
Local & $14 / 38$ & $37^{*}$ \\
General & $26 / 57$ & $46^{*}$ \\
\hline
\end{tabular}

*No significant difference, $\mathrm{p}=0.5246$.

Table 6: Success rate of facet denervation in relieving pain in the presence and absence of aggravation by spinal extension.

\begin{tabular}{lll}
\hline $\begin{array}{l}\text { Pain aggravated } \\
\text { by extension? }\end{array}$ & $\begin{array}{l}\text { Proportion of } \\
\text { successful procedures }\end{array}$ & $\%$ \\
Yes & $18 / 46$ & $39 *$ \\
No & $8 / 17$ & $47 *$ \\
\hline
\end{tabular}

*Not statistically significant, $\mathrm{p}=0.7802$.

Table 7: Complications of facet denervation.

\begin{tabular}{lcl}
\hline & No. of procedures & $\mathbf{\%}$ \\
Pain worse & 4 & 3 \\
Transient neuropathic pain & 12 & 10 \\
Transient leg pain & 1 & 1 \\
Subjective leg weakness & 2 (1 persistent) & 2
\end{tabular}

persistent in one, without any clinical evidence of muscle weakness, wasting or fibrillation.

\section{Discussion}

In our experience in 118 procedures at various levels in the spine, pain relief of at least $50 \%$ was initially achieved in $41 \%$ of the patients. Results were not statistically different at cervical, thoracic or lumbosacral levels, whether unilateral or bilateral facet denervations were done, whether the patient had undergone previous spinal surgery, whether two to three, or more than three facet joints were denervated, or whether local or general anaesthetic was used. If procedures were repeated at the same level in the same patient, the outcomes were similar in the two procedures. Results did not differ between patients in whom pain was aggravated by spinal extension and those in whom it was not. Complications were minimal, there being no objective evidence for intercurrent damage to the ventral rami at the same level.

These results raise a number of issues. Why should facet denervation fail to relieve pain, when local anaesthetic blockade at the same level did? A $41 \%$ overall incidence of pain relief may seem low. In a number of our patients, the denervation was repeated when pain recurred at varying intervals after the initial procedure. Why should the pain recur? The consistency of results when procedures were repeated suggests that in the event of an apparently successful facet denervation procedure failing to relieve the patient's pain, repetition is unlikely to be successful also.

FJs, which provide both mobility and stability of the spinal column, have joint capsules that are richly supplied by nerves coming from the medial branch PPR of the spinal nerves. ${ }^{30-37,39,40}$ Thus, it is possible for FJs to contribute significantly to the sensation of back pain and therefore, their selective denervation may ameleriorate the pain when it arises chiefly in the FJs. FJ pain is recognized by its localization in the neck, thoracic spine or low back that may descend into the proximal portion only of the appropriate limb. ${ }^{6,40-47}$ Spine mobility is often reduced and hyperextension, as well as prolonged standing and sitting, are commonly reported to aggravate it. It is not accompanied by significant neurological deficit or evidence of root irritation. FJ denervation depends on destruction of the PPR or of its medial branch achieving selective denervation of the FJ. Our results do not support the contention that aggravation of pain by spinal hyperextension is typical of FJ pain. Reported success rates with TRFFR range from $20-90 \% ;{ }^{8-29}$ thus our results are in the middle of the reported range and therefore comparable to the results of many. Lord et al, ${ }^{48}$ for example, in 11 patients undergoing 12 procedures between C5 and C7 who had enjoyed excellent temporary relief after careful diagnostic local anaesthetic blockade, reported relief lasting three to six months in 8.3\%, 612 months in $25 \%, 12-24$ months in $8.3 \%$, over 24 months in $16.7 \%$. In $41.7 \%$, pain relief was brief and three denervations were repeated after pain recurrence following the first procedure at intervals of one, two, three, nine and ten months, if we interpret their figure five correctly. There are several possible explanations for reported variations. Patient selection criteria may vary. It has been reported, ${ }^{7,9,23}$ that previous spinal surgery degrades the result but our results do not support this contention; only in the occasional patient did a fusion mass prevent access to the location of the facet nerve. We have no evidence to suggest that the involvement of health insurance and Worker's Compensation is an important factor, as claimed by some. Diagnostic tests are used in some centres to select patients for permanent denervations, but not in others. Shealy ${ }^{6-8}$ did not use diagnostic anaesthetic blocks as a routine preoperative screening 
test but still reported an almost $80 \%$ success rate in patients who had not previously undergone spinal surgery. In different centres diagnostic local blockade is done in different ways, sometimes consisting of local injection into the FJ itself, sometimes into the surrounding capsule outside the joint space, adjacent to the FJ or else directed towards either the posterior ramus or the medial branch of the posterior ramus.,9,21,22,25,28,49-54 Marks et al ${ }^{51}$ performed a randomized comparison of nerve versus joint block in 86 patients with chronic low back pain and concluded that the two techniques were of equal value. Another possible reason for discrepancies between reported results is the use of an ineffective FJ denervation procedure. Bogduc et al ${ }^{12}$ studied the shape and size of the coagulum at the electrode tip obtained by RF ablation and concluded that if the electrodes are directed perpendicularly onto a nerve, the nerve may not be encompassed by the lesion generated. They believed that it was better to approach the nerve longitudinally. In our own cases, one could question whether the appropriate nerve had actually been denervated in those patients where pain relief failed and no sensory alterations occurred in the distribution of the cutaneous branches of the posterior rami. However, there are usually no cutaneous branches in the most commonly lesioned area, the lower lumbar and S1 region, so that this guidance is unavailable there. Another concern is that the local anaesthetic, intended to be introduced into a facet joint or facet nerve, may spread beyond the intended target, thus relieving pain caused by other than FJ disease. Finally, a single brief experience with local blockade may be inadequate. Barnsley et $a{ }^{55}$ in a double blind study of local anaesthetic blockade of the medial branches of the dorsal rami to a single cervical facet joint, found a $27 \%$ false positive response. Other important factors are the extent of facet denervation, the RJ lesion parameters used, the number of lesions made at each level, the number of joints denervated and whether the denervations are done unilaterally or bilaterally.Our results do not suggest that these are all significant factors. Extremely important is the protocol used to evaluate success and the length of follow-up. However, facet denervations are post-ganglionic, so that nerve regeneration is to be expected with pain recurrence after months to a few years, as demonstrated by Lord et al. ${ }^{48}$ Thus pain relief, after very long follow-ups, should not be expected, though it is of great interest when it occurs.

Most series are based on procedures done under local anaesthesia, whereas we used general anaesthesia after 1991. Although one would have expected results to be inferior without the benefit of the patient's reported sensory experience during stimulation, such was not the case, as results were similar in the two groups, even though, under general anaesthetic, only motor effects could be used to localize the lesion. Motor contractions can be obtained by direct electrical stimulation of muscles which are plentiful in the target area. In two cases, the patients were temporarily paralyzed with very short acting myoneural junction blocker under local anaesthesia and motor stimulation was applied both before and after injection of the drug. Paralyzed patients still showed motor contractions when the electrode was placed in muscle bellies but not when they were placed at the expected location of the posterior rami as described in our section on technique. The crucial experiment has not been done, i.e. that of comparing results in a suitably controlled study with and without physiological localization to determine whether anything more than simple radiological localization is necessary.

There remains the problem of why some published success rates reach $90 \%$ whereas ours was only $41 \%$. Beyond issues of technique, patient selection and result evaluation, chronic pain surgery of any type, except that for tic douloureux has a success rate of something under $50 \%$. This includes dorsal column stimulation, deep brain stimulation and various destructive techniques. One would not expect the results of facet denervation to be any different. The results in procedures with such low success rates always raise the issue of the placebo effect. This poorly-understood phenomenon is difficult to assess in uncontrolled studies such as this. In 1996, Lord et al $^{56}$ carried out a randomized double blind trial of percutaneous RF neurotomy compared with a controlled treatment in which the procedure was identical except no RF current was used. Double blind placebo control local anaesthetic trial blockade had been previously carried out and had relieved the pain temporarily. In the patients undergoing true RF lesions, pain returned to at least its $50 \%$ preoperative level after a mean of 263 days. In the placebo control group, pain returned after eight days $(\mathrm{p}=0.04)$. Seven RF lesion patients and one control were still free of pain after 27 weeks and five of the RF lesion group had numbness in the appropriate distribution, that was not a significant problem. Thus, in their hands, with 12 patients undergoing true RF lesioning and 12 undergoing sham lesioning, there was a six month placebo effect in $1 / 12$ but pain had recurred in $5 / 12$ of the lesioned patients.

In the articles reviewed, complications were very rare and often not even mentioned. We have seen certain minor complications, especially neuropathic pain from the interruption of the FJ nerve supply from C2 to L2. The incidence of postoperative neuropathic pain was statistically significantly higher in the cervical or thoracic compartment ( 9 out of 30 cases) than it was in the lumbosacral ( 3 out of 86 cases) $\left(p=3.9 \times 10^{-5}\right)$. This reflects the absence of cutaneous branches of the posterior rami in the lower lumbar and $\mathrm{S} 1$ areas.

\section{CONCLUSION}

PRFFR is a safe, simple and moderately effective procedure for the temporary relief of pain originating in facet joints although a rigorous attention to the details of the technique is required. It appears equally effective in patients who have, and those who have not, had previous spinal surgery. Whether physiological localization enhances the success rate or not, it is our opinion that it is essential for the avoidance of inadvertent damage to anterior rami. It is equally applicable in the cervical, thoracic and lumbar areas but requires special care in the upper cervical region. Above the level of the lower lumbar facets, sensory loss may be expected in the distribution of the cutaneous branches of the posterior rami, which is, in our experience, sometimes associated with transient neuropathic pain. If RF facet denervation is unsuccessful in relieving the patient's pain, it is unlikely that a repeated procedure will improve the result. We describe a technique for performing the procedure under general anaesthesia, which appears to be as successful as when local anaesthetic is used and which significantly shortens the procedure and avoids much patient discomfort. 


\section{REFERENCES}

1. Goldthwait JE. The lumbosacral articulation. An explanation of many cases of "lumbago, sciatica, and paraplegia". Boston Med Surg J 1911; 164:356-372.

2. Putti V. New conceptions in the pathogenesis of sciatic pain. Lancet 1927; 2: 53-60.

3. Ghormley RK. Low back pain with special reference to the articular facets, with presentation of an operative procedure. JAMA1933; 101:1773-1777.

4. Badgley CE. The articular facets in relationship to low back pain and sciatic radiation. J Bone Joint Surg Am 1941; 23: 481-496.

5. Rees WES. Multiple bilateral subcutaneous rhizolysis of segmental nerves in the treatment of the intervertebral disc syndrome. Ann Gen Pract 1971; 26:126-127.

6. Shealy CN. The role of the spinal facets in back and sciatic pain. Headache 1974; 14:101-104.

7. Shealy CN. Percutaneous radiofrequency denervation of spinal facets: treatment for chronic back pain and sciatica. J Neurosurg $1975 ; 43: 448-451$.

8. Shealy CN. Facet denervation in the management of back and sciatic pain. Clin Orthop 1976; 115:157-164.

9. Babur H. Facet rhizotomy for cervical radiculitis. Mt Sinai J Med 1994; 61:265-271.

10. Banerjee T, Pittman HH. Facet rhizotomy: another armamentarium for treatment of low backache. NCMJ 1976; 37:354-360.

11. Bogduk N, Long DM. Percutaneous lumbar medial branch neurotomy: a modification of facet denervation. Spine 1980; 5:193-200.

12. Bogduk N, Macintoch J, Marsland A. Technical limitations to the efficacy of radiofrequency neurotomy for spinal pain. Neurosurgery 1987; 20:529-535.

13. Burton C. Percutaneous radiofrequency facet denervation. Appl Neurophysiol 1976; 39:80-86.

14. Florez G, Eiras J, Ucar S. Percutaneous rhizotomy of the articular nerve of Luschka for low back and sciatic pain. Acta Neurochir (suppl) 1977; 24:67-71.

15. Florez G, Eiras J, Ucar S. Radiofrequncy facet denervation in the treatment of persistent headache associated with chronic neck pain. J Neurol Orthop Surg 1980;1:127-130.

16. King JS. Randomized trial of the Rees and Shealy methods for the treatment of low back pain. In: Morley TP ed: Current Controversies in Neurosurgery. Philadelphia: WB Saunders, 1976: 89-94.

17. Lord SM, Barnsley L, Bogduk N. Percutaneous radiofrequency neurotomy in the treatment of cervical zygapophysial joint pain: a caution. Neurosurgery 1995;36:732-739.

18. Lord M, Barnsley L, Wallis BJ, McDonald GJ, Bogduk N. Percutaneous radio-frequency neurotomy for chronic cervical zygapophyseal-joint pain. N Engl J Med 1996;335:1721-1726.

19. McCulloch JA. Percutaneous radiofrequency lumbar rhizolysis (rhizotomy). Appl Neurophysiol 1976; 39:87-96.

20. McCulloch JA, Organ LW. Percutaneous radiofrequency lumbar rhizolysis. CMAJ 1977; 116:30-32.

21. Mehta M, Sluijter ME. The treatment of chronic back pain: a preliminary survey of the effect of radiofrequency denervation of the posterior vertebral joints. Anaesthesia 1979; 34:768-775.

22. Ogsbury JS, Simon RH, Lehman RAW. Facet "denervation" in the treatment of low back syndrome. Pain 1977; 3:257-263.

23. Oudenhoven RC. Articular rhizotomy. Surg Neurol 1974; 2:275-278.

24. Pawl RP. Results in the treatment of low back syndrome from sensory neurolysis of the lumbar facets (facet rhizotomy) by thermal coagulation. Proc Inst Med Chic 1974; 30:151-152.

25. Rashbaum RF. Radiofrequency facet denervation: a treatment alternative in refractory low back pain with or without leg pain. Orthop Clin North Am 1983; 14:569-575.

26. Schaerer JP. Radiofrequency facet rhizotomy in the treatment of chronic neck and low back pain. Int Surg 1978; 63:53-59.

27. Schaerer JP. Treatment of prolonged neck pain by radiofrequency facet rhizotomy. J Neurol Orthop Med Surg 1988;9:74-76.

28. Silvers HR. Lumbar percutaneous facet rhizotomy. Spine 1990; 15:36-40.
29. Vervest ACM, Stoler RJ. The treatment of cervical pain syndromes with radiofrequency procedures. Pain Clin 1991;4:103-112.

30. Auteroche P. Innervation of the zygapophysial joints of the lumbar spine. Anatl Clin 1983; 5:17-28.

31. Bogduk N, Long DM. The anatomy of the so-called "articular nerves" and their relationship to facet denervation in the treatment of low back pain. J Neurosurg 1979; 51:172-177.

32. Bogduk N. The clinical anatomy of the cervical dorsal rami. Spine 1982; 7:319-330.

33. Bogduk N, Wilson AS, Tynan W. The human lumbar dorsal rami. J Anat 1982; 134:383-397.

34. Edgar MA, Ghadially JA. Innervation of the lumbar spine. Clin Orthop 1976; 115:35-41.

35. Groen GJ, Baljet B, Drukker J. Nerves and nerve plexuses of the human vertebral column. Am J Anat 1990; 188:282-296.

36. Lewin T, Moffett B, Viidik A. The morphology of the lumbar synovial intervertebral joints. Acta Morphol Neerl Scand 1962; 4:299-319.

37. Pedersen HE, Blunck CFJ, Gardner E. The anatomy of lumbar posterior rami and meningeal branches of spinal nerves (sinuvertebral nerves) with an experimental study of their function. $\mathbf{J}$ Bone Joint Surg Am 1956; 38:377-391.

38. Mooney V. Facet syndrome. In: Weinstein JN, Wiesel SW eds. The Lumbar Spine: The International Society for the Study of the Lumbar Spine. Philadelphia: WB Saunders, 1990: 422-441

39. Bradley KC. The anatomy of backache. Aust NZ J Surg 1974; 44:227-232.

40. Fox JL, Rizzoli HV. Identification of radiologic coordinates for the posterior articular nerve of Luschka in the lumbar spine. Surg Neurol 1973; 1:343-346.

41. Bogduk N, Marsland A. The cervical zygapophysial joints as a source of neck pain. Spine 1988; 13:610-617.

42. Donovan WH, Dwyer AP, White BW, et al. A multidisciplinary approach to chronic low-back pain in western Australia. Spine 1981; 6:591-597.

43. Lilius G, Laasonen EM, Myllynen P, Harilainen A, Groniund G. Lumbar facet joint syndrome: a randomised clinical trial. J Bone Joint Surg Br 1989; 71:681-684.

44. Mehta M, Parry CB. Mechanical back pain and the facet joint syndrome. Disabil Rehabil 1994; 16:2-12.

45. Mooney V, Robertson J. The facet syndrome. Clin Orthop 1976; 115:149-156.

46. Snewing G. Facet joint syndrome: a review. Physiotherapy Canada 1984; 36:141-144

47. Wetzel FT. Chronic benign cervical pain syndrome: surgical considerations. Spine 1992; 17:S367-S374.

48. Lord SM, Barnsley L, Bogduk N. Percutaneous radiofrequency neurotomy in the treatment of cervical zygapophyseal joint pain: a caution. Neurosurgery 1995;36: 732-739.

49. Lippitt AB. The facet joint and its role in spine pain: management with facet joint injections. Spine 1984; 9:746-750.

50. Lord SM, Barnsley L, Bogduk N. The utility of comparative local anesthetic blocks versus placebo-controlled blocks for the diagnosis of cervical zygapophysial joint pain. Clin J Pain 1995; 11:208-213.

51. Marks RC, Houston T, Thulbourne T. Facet joint injection and facet nerve block: a randomised comparison in 86 patients with chronic low back pain. Pain 1992; 49:325-328.

52. Revel ME, Listrat VM, Chevalier XJ, et al. Facet joint block for low back pain: identifying predictors of a good response. Arch Phys Med Rehabil 1992; 73:824-828.

53. Stolker RJ, Vervest ACM, Groen GJ. The management of chronic spinal pain by blockades: a review. Pain 1994; 58:1-20.

54. Wood L. Acute locked facet syndrome and its treatment by manipulation under local periarticular anaesthesia: Part 1 . Clinical perspective and pilot study proposal. J Manipulative Physiol Ther 1984; 7:211-217.

55. Barnsley L, Lord S, Wallis B, Bogduk N. False-positive rates of cervical zygaphophyseal joint blocks. Clin J Pain 1993;9:124-130.

56. Lord SM, Barnsley L, Wallis BJ, McDonald GJ, Bogduk N. Percutaneous radio-frequency neurotomy for chronic cervical zygaphophyseal-joint pain. N Engl J Med 1996;335:1721-1726. 